\title{
An Evaluation System and Its Model for Educational Competitiveness of Universities
}

\author{
https://doi.org/10.3991/ijet.v15i11.14521 \\ Lin Lin \\ Beihua University, Jilin, China \\ 67871462@qq. com
}

\begin{abstract}
There are several defects with the current evaluation strategy for educational competitiveness of universities, namely, the lack of a well-established evaluation system and the complexity of evaluation factors. To overcome these defects, this paper analyzes the key factors affecting the educational competitiveness of universities, and establishes an evaluation system covering such three aspects as basic input, progress and output. On this basis, an evaluation model was created to assess the educational competitiveness of universities, in the light of multiple factors on varied levels. Overall, our evaluation system and its model can effectively achieve the multi-factor evaluation of the educational competitiveness of universities, providing a good solution to complex system decision-making problems.
\end{abstract}

Keywords - Educational competitiveness, universities, evaluation system, evaluation model, fuzzy system theory

\section{Introduction}

Higher education provides a large number of high-quality talents for the rapid development of modern society, and offers a manpower and technical reserves for promoting the development and innovation of different social fields. Higher education is now playing an irreplaceable role in improving the overall competitiveness of the country and the society; therefore, the development of higher education has been valued by more and more people [1-3]. The educational competitiveness of universities has gradually become a hot issue in higher education research. As the subject that implements the higher education, universities are the base for cultivating senior talents. The educational competitiveness of universities not only reflects the educational level of universities, it's also a major indicator reflecting the sustainable development of the country and the society. As a result, improving the educational level and competitiveness of universities is of great scientific and developmental significance [4-6].

At present, some researchers have analyzed the educational competitiveness of universities from different perspectives, and proposed a series of insights and research results, which have a positive effect on improving the educational competitiveness of universities. For example, ZHOU discussed the measures and strategies to improve the educational competitiveness of local colleges and universities in the context of 
internationalization [7]. WEN et al. identified the special competitive advantages of higher education in China and proposed corresponding improvement strategies [8]. Dulma Dugarova et al. discussed how to improve the competitiveness of higher education in cross-border areas based on education auditing, and pointed out that education auditing is the only way to improve the competitiveness of higher education in crossborder areas [9].

Moreover, Nicole C. Jackson explored the issue of competence management in the innovation and transformation of higher education, and discussed how higher education can better manage the transformation of new competences and the innovation requirements brought by the emergence of digital technologies in the process of digital transformation [10]. Wang et al. established a higher education competitiveness analysis index model, then based on this model and relevant index, they compared the competitiveness of higher education in China with other countries in the world [11]. Carolin Plewa et al. analyzed the impact of higher education reputation on its competitiveness and discussed a fuzzy set analysis method based on resource allocation [12].

However, colleges and universities generally have the characteristics of multiple disciplines, majors and levels, for example, some universities focus on science and engineering, some focus on liberal arts and social science; some focus on the education of application-oriented talents, and some focus on the education of quality-oriented talents, etc.; and different researchers often have disparate perspectives on the competitiveness of universities, which makes their analysis of the competitiveness of universities too general to form a system, so it's necessary to conduct further research on the evaluation of the competitiveness of universities. For this reason, based on a review of the relevant literatures and research results, this paper studies the evaluation of the educational competitiveness of universities under the guidance of the fuzzy system theory [13-16]. There're five parts in this paper: the first part gives an introduction of the educational competitiveness of current universities; the second part analyzes the influencing factors of the educational competitiveness of current universities; the third part constructs an evaluation system of the educational competitiveness of the universities; the fourth part discusses the evaluation methods of the educational competitiveness of the universities; and the fifth part is the conclusion.

\section{Influencing Factors of Educational Competitiveness of Universities}

\subsection{Insufficient basic input}

Basic input is a key factor affecting the educational competitiveness of universities. The size of the basic input reflects the development potential of a university, there are two aspects of basic input: hardware input and software input. Hardware input mainly refers to the human, material and financial resources invested by universities during the development of education; and the software input refers to the universities' investment and emphasis on the educational environment, planning, management and concept during the development of education. Generally speaking, the capital source of the basic 
input in universities mainly comes from the government, school and society. Due to the different natures, types and levels of colleges and universities, there are certain limitations in the basic input, for instance, for universities that are directly subordinate to the government, they often have preferential policies in their basic input and they can obtain more funding resources, so their educational competitiveness is stronger. As for universities that are not directly subordinate to the government, they usually need social endowments or the school's profitable management activities to provide capitals for their basic input, as a result, insufficient social resources or improper profitable management will directly affect their basic input in the school education. In addition, under the guidance of the science and technology development policy, universities of science and technology often receive more funding from the government for their basic input; while for universities of liberal arts, they can hardly get as much funding from the government as the universities of science and technology. Due to the influence of government, the social environment, and the school's development status, universities of different types, attributes and levels vary greatly in their basic input, resulting in that their development status is uneven. This study believes that, in order to improve the educational competitiveness of universities, especially the universities that are not directly subordinate to the government, they must pay more attention to the utilization and integration of social resources, enlarge the scope of cooperation between universities and social organizations, and enhance industry-university-research cooperation between universities and enterprises.

\subsection{Unbalanced discipline setting}

The unbalanced discipline setting in universities is an important factor affecting their educational competitiveness. At present, universities generally attach great importance to the research output, including science projects, research papers, scientific awards, monographs, and patents, etc., and the research funding is often taken as a symbol of the development level of the school. A university with more research funding and output is often considered to have a higher teaching level and stronger educational competitiveness; while a university with less research funding and output is considered to have a lower teaching level and weaker educational competitiveness. Such evaluation method has led to that many universities lay great emphasis on scientific research while neglecting the teaching practice, and the cultivated students are just derivatives of scientific projects, which cannot truly reflect the educational competitiveness of the schools. This paper takes the comprehensive universities as the subjects to illustrate that, since the research funding and output of science majors are taken as the primary part of the universities' research funding and output, when the schools are formulating related policies, they would give priorities to the development of science and engineering disciplines, which has inevitably resulted in uneven development levels of science majors and liberal arts, in the long run, science majors develop better and better while the liberal arts can hardly keep up with the needs of social development due to insufficient basic input, and this situation has promoted the formation of the developmental trend that the science and engineering disciplines are dominating the higher education. 
However, the educational competitiveness of universities is essentially a manifestation of the comprehensive development ability of multiple disciplines in the schools, in particular, as the higher education aims to cultivate high-quality modern talents, the students need to have not only the scientific research qualities, but also the humanistic qualities, and only such students with higher comprehensive qualities could better satisfy the demands of the social development. Therefore, our study believes that, in the course of improving the educational competitiveness of universities, we should pay attention to the balanced development of various disciplines, especially in liberal arts disciplines, more investment, preferential policies and supporting ideas should be provided to them so that the development of liberal arts could compete with the progress of science and engineering disciplines, thereby better promoting the educational competitiveness of universities.

\subsection{Inadequate sustainable development of faculty}

The faculty of universities is the manpower reserve for the development of higher education, and the faculty construction is an important part for promoting the educational competitiveness of universities. An important feature that can measure whether the educational competitiveness of a university is sustainable is whether the school has a faulty team with a hierarchical structure during the development of the disciplines. The meaning of a faulty team with a hierarchical structure has several aspects: the first is that the professional qualifications of the faulty have a low-mediumhigh hierarchical structure; the second is that the age of the faulty have an old-middleyoung hierarchical structure; and the third is that the senior talent reserves of the faculty have the characteristic of fluidity, that is, we must make sure that the teaching talents be mobile and communicative, so that the faculty could fully exchange with the outside and learn from others, and constantly add fresh blood to the education force. However, in current universities, for some disciplines and majors, there is neither a shaped professional faulty team, nor has the ability to build one, as a result, the development of these disciplines or majors are not able to meet the requirement in the cultivation of high-quality talents, and this situation is quite common in liberal arts disciplines and majors. In some universities, there's no key discipline or major in liberal arts, let alone the key laboratories or research offices; moreover, due to the expansion of student recruitment in certain periods of time, the number of teachers assigned or allowed to have professional titles also runs out, resulting in a disconnected faculty talent hierarchy, which has seriously hindered the sustainable development of higher education and weakened the educational competitiveness of universities. In this study, we believe that, in order to promote sustainable development of university faculty, we have to master the characteristics of the three hierarchies during the construction of university faulty team, and cultivate, introduce and exchange the teaching talents in a targeted manner. 


\subsection{Incomplete education administration system}

Education administration system is an important guarantee for the educational competitiveness of universities. The rules and regulations of universities provide a direction for the implementation of higher education. Only when the direction of education administration is correctly guided can the implementation of education be efficient and of high quality, otherwise, the development of higher education may get half the result with twice the effort. Therefore, the implementation of higher education needs to be carried out under normative rules and regulations, and this is very important and necessary for formulating a higher education administration system suitable for the cultivation of high-quality talents in modern society. However, due to inadequate administrative ability of school leaders and the fact that different schools may be subordinate to different departments, the formulation of university administration policies often hasn't got a uniform implementation standard, and the formulated standards are flawed in normativity and rationality. Especially with the alternation of university leadership, the education administration system of the universities is in constant changing all the time, and the formulated education administration system cannot be implemented effectively, and become a mere decoration. This situation has resulted in a huge waste of manpower, material, and financial resources, and made the education administration system aimless and unformal. Teachers' teaching and researching activities are often based on utilitarian rather than education, which in turn leads to plan less, unsystematic and unscientific implementation of higher education, and low-grade and inefficient education quality, and thereby causing a disconnection between social development demands and the goal of cultivating senior and high-quality talents, which has seriously hindered the improvement of the educational competitiveness of universities. Our study believes that, to formulate a sound higher education administration system, we mustn't focus only on immediate interests, instead, we should formulate the system from the perspective of the concept of scientific development and according to current social environment, the schools' conditions, and the development trend of higher education; the leaders should have strong administration ability and decision-making skills, and fully consider the suggestions of front-line teachers, because they have a better understanding of the problems existing in the implementation process of higher education, and they are able to give effective solutions to these problems.

\section{Evaluation System for The Educational Competitiveness of Universities}

Based on the above analysis of the influencing factors of the educational competitiveness of universities, this paper believes that the construction of the evaluation system for the educational competitiveness of universities could be conducted from three aspects: basis input, progress, and output. 


\subsection{Evaluation of basic input}

The basic input of university education includes two parts: hardware input and software input.

Hardware input: Hardware input is the basic condition for guaranteeing the operation of universities. This section mainly focuses on the basic input of universities during the operation, including the educational expenditure, the recruitment size, the teaching facilities, the faculty and teaching standard, etc.; wherein the educational expenditure could be divided into teaching expenditure, research expenditure, and infrastructure expenditure. In order to subdivide the size of educational expenditure, the educational expenditure per teacher and the educational expenditure per student are generally adopted for analysis. The recruitment size mainly refers to the number of teachers in the faculty team and the number of students on campus, the number of teachers in the faculty team includes the number of teachers and the number of researchers, the number of students on campus can be divided into the number of undergraduates, the number of postgraduates, and the number of international students, etc. The teaching facilities mainly include teaching venues, research venues, libraries, laboratories, auxiliary teaching and researching venues, etc. The faculty and teaching standard mainly refer to the number and proportion of teachers with doctorates or senior professional titles, the number and proportion of teachers with master's degrees or medium-grade professional titles, and the number and proportion of teachers who have been awarded the title of innovative talents at all levels.

Software input: Software input refers to the education policies, systems, concepts applied in the universities, including the educational philosophy, the teaching administrative policies and mechanisms, the research administrative policies and mechanisms, the laboratory administrative policies and mechanisms, the education methods, the campus culture and school motto, and the education strategies, etc. The universities need to examine whether their educational philosophy is consistent with the requirements of the society and the country, and meanwhile pay attention to the epochal and developmental characteristics of the educational philosophy. As for the teaching administrative policies and mechanisms, the research administrative policies and mechanisms, the laboratory administrative policies and mechanisms, they mainly examine the supportive role of higher education, and the rationality and scientificity are their main characteristics. The education methods and strategies mainly examine the effectiveness of the promotion of education quality in the universities. The campus culture and school motto are the reflections of the cultural spirit of the universities during the implementation of higher education.

\subsection{Evaluation of progress}

The progress of higher education refers to the implementation process of administrative policies, educational philosophy, planning measures, implementation methods and related practical activities adopted to improve the educational competitiveness of universities, it includes two major parts: research progress and teaching progress. 
Research progress: The research progress can reflect a university's scientific research level and ability during the implementation of higher education, its measuring indicators include: the number of national key disciplines or majors, the number of provincial or ministerial key disciplines or majors, the number of national key laboratories (including the number of research bases or centers, etc.), the number of provincial and ministerial key laboratories (including the number of research bases or centers, etc.), the number of national scientific research programs, the number of provincial and ministerial scientific research programs, received funds for vertical research programs (vertical research programs mainly focus on basic applications), received funds for horizontal research programs (horizontal research programs mainly focus on engineering applications), the number of industry-university-research cooperation platforms, the number of international cooperation exchange funds or projects, the number of teachers with the research talent titles above the provincial and ministerial levels, the number of international academic conferences attended, etc.

Teaching progress: The teaching progress mainly reflects the teaching level and ability of the universities during the implementation of higher education, its measuring indicators include: the number of national-level excellent courses, the number of provincial-level excellent courses, the number of national-level excellent teachers, the number of provincial-level excellent teachers, the number of national-level teaching materials, the number of provincial-level teaching materials, the number of nationallevel teaching reform programs undertaken, the number of provincial-level teaching reform programs undertaken, the number and times of model courses, the advancement and scientificity of the teaching concept and methods, the rationality of the application of intelligent technologies in education, the epochal nature of teaching content and teaching mode, and the number of visiting scholars sent for further studies, etc.

\subsection{Evaluation of output}

Quality of students: The main goal of higher education is to cultivate high-level and high-quality talents, so the quality of students is one of the key links for the evaluation of the output of universities. The quality of students can be evaluated from several aspects, including the number of undergraduates, the number of postgraduates, the proportion of excellent undergraduates, the proportion of excellent postgraduates, the number of international students, the proportion of excellent international students, number of awards in international university student competitions and the number of student winners, the number of awards in national university student competitions and the number of student winners, the number of awards in provincial and ministerial university student competitions and the number of student winners, the number of students participating in international academic conferences, the number of students giving speeches in international academic conferences, the number of high-level academic papers published by students, the number of excellent doctoral dissertations at the national level (number of students/times), the number of excellent doctoral dissertations at the provincial or ministerial level (number of students/times), the number of excellent master's theses at the provincial or ministerial level (number of students/times), and the number of students sent for further studies, etc. 
Social service ability: Social service ability mainly examines whether the social contribution ability and adaptability of the schools and students can fully adapt to the requirement of social development, and whether the schools and the students could make contributions to the development of the society. Generally speaking, the social service ability can be evaluated from the following aspects: the students' innovation ability, the students' coordination and adaptation ability, employment rate of graduated students, the number of graduated students employed by Fortune 500 companies, the number of graduated students employed by national well-known companies, the proportion of graduated students employed by Fortune 500 companies, the proportion of graduated students employed by national well-known companies, the satisfaction of employers, the number of school-enterprise cooperated social service platforms (centers or bases), the ability of schools to cooperate with social institutions, the schools' social service contribution ability, and the social satisfaction, etc.

Achievement transformation ability: Achievement transformation ability is another important key link for the evaluation of the output of universities, it is the most direct reflection of the educational output of universities, and it has a very important promotive effect in improving the educational competitiveness of universities. The ability to transform the educational achievements of universities can be evaluated from the following aspects: the number of identified international scientific and technological achievements, the number of identified national scientific and technological achievements, the number of provincial and ministerial scientific and technological achievements, the number of national natural science awards (including awards for inventions, and awards for scientific and technological advancement, etc.), the number of provincial and ministerial natural science awards (including awards for inventions, and awards for scientific and technological advancement, etc.), the number of national teaching reform awards, the number of provincial and ministerial teaching reform awards, the funds for industry-university-research cooperation, the funds for scientific and technological achievements transfer contracts, the scientific and technological achievement transformation rate, the teaching reform achievement transformation rate, the number of high-quality scientific and technological papers, the number of invention patents authorized, the number of monographs published by well-known international or domestic publishers, and the number of textbooks published by well-known international or domestic publishers, etc.

\section{Evaluation Method for the Educational Competitiveness of Universities}

Based on above analysis, this paper took the educational competitiveness of universities as the objective layer of the evaluation, the universities' basic input, progress, and output were taken as the criteria layer, under each criterion, there're corresponding multi-level evaluation indices. 


\subsection{Processing of evaluation indices}

According to the content of the evaluation indices of the educational competitiveness of universities, it can be known that the evaluation indices include various types, such as benefit-type indices and cost-type indices, and different types of evaluation indices have different dimensions. In order to have a unified standard for evaluating the educational competitiveness of universities, it is necessary to standardize the evaluation indices. At the same time, because the value of the evaluation index is often fuzzy, this paper adopted the triangular fuzzy number to describe the value of the evaluation index.

For the $\mathrm{i}$-th $i(1 \leq i \leq n)$ evaluation object, the value $V_{i j}$ of the triangular fuzzy number of the $\mathrm{j}$-th $j(1 \leq j \leq m)$ evaluation index of the educational competitiveness of universities can be expressed as:

$$
V_{i j}=\left[v_{i j}^{M i d}, v_{i j}^{\Delta-L e f}, v_{i j}^{\Delta-R i g}\right]
$$

where, $v_{i j}^{\text {Mid }}$ represents the optimal value of the evaluation index of the educational competitiveness of universities, $v_{i j}^{\Delta-L e f}$ represents the left deviation of the optimal value of the evaluation index of the educational competitiveness of universities, $v_{i j}^{\Delta-R i g}$ represents the right deviation of the optimal value of the evaluation index of the educational competitiveness of universities.

In particular, if the values of the evaluation indices of the educational competitiveness of universities were described by fuzzy intervals, they can be converted into the form of triangular fuzzy numbers. If the values of the evaluation indices are expressed as $U_{i j}=\left[u_{i j}^{\operatorname{Min}}, u_{i j}^{\operatorname{Max}}\right]$, the conversion process can be expressed as follows:

$$
\left\{\begin{array}{l}
V_{i j}=\left[v_{i j}^{M i d}, v_{i j}^{\Delta-L e f}, v_{i j}^{\Delta-R i g}\right] \\
v_{i j}^{M i d}=\frac{u_{i j}^{M i n}+u_{i j}^{M a x}}{2} \\
v_{i j}^{\Delta-L e f}=v_{i j}^{\Delta-R i g}=\frac{u_{i j}^{M a x}-u_{i j}^{M i n}}{2}
\end{array}\right.
$$

If the evaluation index of the educational competitiveness of universities is a benefittype index, then the normalized evaluation index value can be expressed as:

$$
R_{i j}=\left[r_{i j}^{M i d}, r_{i j}^{\Delta-L e f}, r_{i j}^{\Delta-R i g}\right]=\left[\frac{v_{i j}^{M i d}}{\max _{1 \leq i \leq n}\left(V_{i j}\right)}, \frac{v_{i j}^{\Delta-L e f}}{\max _{1 \leq i \leq n}\left(V_{i j}\right)}, \frac{v_{i j}^{\Delta-R i g}}{\max _{1 \leq i \leq n}\left(V_{i j}\right)}\right]
$$

If the evaluation index of the educational competitiveness of universities is a costtype index, then the normalized evaluation index value can be expressed as: 


$$
R_{i j}=\left[r_{i j}^{M i d}, r_{i j}^{\Delta-L e f}, r_{i j}^{\Delta-R i g}\right]=\left[\frac{\min _{1 \leq i \leq n}\left(V_{i j}\right)}{v_{i j}^{M i d}}, \frac{\min _{1 \leq i \leq n}\left(V_{i j}\right)}{v_{i j}^{\Delta-L e f}}, \frac{\min _{1 \leq i \leq n}\left(V_{i j}\right)}{v_{i j}^{\Delta-R i g}}\right]
$$

It can be seen that the normalized evaluation indices of the educational competitiveness of universities were all in the range of 0 - 1 , and all evaluation indices had a uniform measuring standard.

\subsection{Triangular fuzzy number}

Existing evaluation methods include AHP method, entropy weight method, genetic algorithm, grey correlation analysis, and neural network, etc. [17-22], but these methods have their corresponding scopes of application, some methods are more subjective, which would affect the objectivity of the evaluation results; some methods require a large number of data samples; some have a complicated computation process; and some cannot effectively deal with fuzzy information. To this end, this paper adopted the fuzzy system theory to analyze the educational competitiveness of universities, and proposed an evaluation model for the educational competitiveness of universities based on the triangular fuzzy number [23-25].

The maximum value of the normalized evaluation index has been selected as the benchmark for the best evaluation $R_{j}^{\Omega}$, that is:

$$
R_{j}^{\Omega}=\left[\max _{1 \leq i \leq n}\left(r_{i j}^{M i d}\right), \max _{1 \leq i \leq n}\left(r_{i j}^{\Delta-L e f}\right), \max _{1 \leq i \leq n}\left(r_{i j}^{\Delta-R i g}\right)\right]
$$

The minimum value of the normalized evaluation index has been selected as the benchmark for the worst evaluation $R_{j}^{\mho}$, that is:

$$
R_{j}^{\mho \mho}=\left[\min _{1 \leq i \leq n}\left(r_{i j}^{\text {Mid }}\right), \min _{1 \leq i \leq n}\left(r_{i j}^{\Delta-L e f}\right), \min _{1 \leq i \leq n}\left(r_{i j}^{\Delta-R i g}\right)\right]
$$

Accordingly, the best benchmark set $\mathbf{R}^{\Omega}$ and the worst benchmark set $\mathbf{R}^{\Omega}$ of the evaluation indices of the educational competitiveness of universities were expressed as follows:

$$
\left\{\begin{array}{l}
\mathbf{R}^{\Omega}=\left\{R_{1}^{\Omega}, \cdots, R_{j}^{\Omega}, \cdots, R_{m}^{\Omega}\right\} \\
\mathbf{R}^{\mho}=\left\{R_{1}^{\mho}, \cdots, R_{j}^{\mho}, \cdots, R_{m}^{\mho}\right\}
\end{array}\right.
$$

Then the fuzzy distance $D_{i j}^{\Omega}$ of the i-th $i(1 \leq i \leq n)$ evaluation object and the best benchmark set $\mathbf{R}^{\Omega}$ on the j-th $j(1 \leq j \leq m)$ evaluation index can be expressed as: 


$$
D_{i j}^{\Omega}=\sqrt{\frac{\left(\max _{1 \leq i \leq n}\left(r_{i j}^{M i d}\right)-r_{i j}^{M i d}\right)^{2}+\left(\max _{1 \leq i \leq n}\left(r_{i j}^{\Delta-L e f}\right)-r_{i j}^{\Delta-L e f}\right)^{2}+\left(\max _{1 \leq i \leq n}\left(r_{i j}^{\Delta-R i g}\right)-r_{i j}^{\Delta-R i g}\right)^{2}}{3}}
$$

Then the fuzzy distance $D_{i j}^{\mho}$ of the i-th $i(1 \leq i \leq n)$ evaluation object and the worst benchmark set $\mathbf{R}^{\mho}$ on the j-th $j(1 \leq j \leq m)$ evaluation index can be expressed as:

$$
D_{i j}^{\mho}=\sqrt{\frac{\left(\min _{1 \leq i \leq n}\left(r_{i j}^{M i d}\right)-r_{i j}^{M i d}\right)^{2}+\left(\min _{1 \leq i \leq n}\left(r_{i j}^{\Delta-L e f}\right)-r_{i j}^{\Delta-L e f}\right)^{2}+\left(\min _{1 \leq i \leq n}\left(r_{i j}^{\Delta-R i g}\right)-r_{i j}^{\Delta-R i g}\right)^{2}}{3}}
$$

\subsection{Implementation of the evaluation model}

According to the physical meaning of the model, it can be known that, the closer the evaluation object to the best benchmark set $\mathbf{R}^{\Omega}$, the smaller the distance $D_{i j}^{\Omega}$ between the two, and the better the evaluation object; on the contrary, the closer the evaluation object to the worst benchmark set $\mathbf{R}^{v}$, the smaller the distance $D_{i j}^{v}$ between the two, and the worse the evaluation object. If the weight of the j-th $j(1 \leq j \leq m)$ evaluation index is $w_{j}$, then the weighted fuzzy nearness $\psi_{i}^{\Omega}$ between the evaluation object and the best benchmark set $\mathbf{R}^{\Omega}$ is:

$$
\psi_{i}^{\Omega}=\sum_{j=1}^{m}\left(w_{j} *\left(1-D_{i j}^{\Omega}\right)\right)
$$

Similarly, weighted fuzzy nearness $\psi_{i}^{\text {ซ }}$ between the evaluation object and the worst benchmark set $\mathbf{R}^{\mho}$ is:

$$
\psi_{i}^{\mho}=\sum_{j=1}^{m}\left(w_{j} *\left(1-D_{i j}^{\mho}\right)\right)
$$

From this, we can obtain the comprehensive weighted fuzzy nearness $\psi_{i}$ of the evaluation object of the educational competitiveness of the universities, that is:

$$
\psi_{i}=\frac{1}{1+\left(\left(1-\psi_{i}^{\mho}\right) /\left(1-\psi_{i}^{\Omega}\right)\right)^{2}}
$$

Therefore, the comprehensive weighted fuzzy nearness $\psi_{i}$ could be sorted according to its size, the larger the value of $\psi_{i}$, the stronger the educational competitiveness of the evaluation object; conversely, the smaller the value of $\psi_{i}$, the weaker the educational competitiveness of the evaluation object. 


\section{Conclusion}

This paper analyzed the influencing factors of the educational competitiveness of universities from the aspects of basic input, discipline construction, faculty team construction and administration system, and pointed out the ways to improve the educational competitiveness of universities; from the perspectives of basic input, progress, and output, the paper constructed an index evaluation system for the educational competitiveness of universities. At the same time, the paper compared the existing evaluation methods and proposed a fuzzy decision analysis model for evaluating the educational competitiveness of universities, which has important application value for the quantitative analysis of the evaluation of the educational competitiveness of universities, meanwhile, the model also has good applicability for solving the decision-making problems of other complex systems with similar characteristics.

\section{Acknowledgement}

The project of Jilin Province in 13th Five-Year (NO. GH19720).

\section{$7 \quad$ References}

[1] Liu, Y.R. (2018). Innovation and practical exploration of teaching reform of continuing education guided by social competitiveness -- Taking the practice of overseas Chinese higher education institutions as the research object. Continuing Education, (3): 7-10. https://doi.org/ 10.13981/j.cnki.cn11-3315/g4.2018.03.002.

[2] Kang, K., Gao, X.J. (2019). The Core of the Construction of Advanced Higher Education System in China: Improving the Competitiveness of Higher Education. Journal of Adolescent Health, (7): 8-13.

[3] Suartama, I.K., Setyosari, P., Sulthoni, Ulfa, S. (2019). Development of an instructional design model for mobile blended learning in higher education. International Journal of Emerging Technologies in Learning, 14(16): 4-22. https://doi.org/10.3991/ijet.v14i16.10 $\underline{633}$

[4] Tang, X.L. (2018). A Comparative Study on the Competitiveness of Higher Education in the "BRIC". Modern Education Management, 9: 123-128. https://doi.org/10.16697/j.cnki. xdjygl.2018.09.022.

[5] Raman, A. (2019). Potentials of fog computing in higher education. International Journal of Emerging Technologies in Learning, 14(18): 194-202. https://doi.org/10.3991/ijet.v14 $\underline{\mathrm{i} 18.10765}$

[6] Liu, N.N. (2017). A Study on the Competitiveness and Coordinated Development of the Provincial Graduate Education in China. Modern Education Management, (9): 102-107. https://doi.org/10.16697/j.cnki.xdjygl.2017.09.019.

[7] Zhou, C.T. (2019). Research and Practice on the core competitiveness of Local Universities under the background of education internationalization. Policy Research \& Exploration, (5): 52-53. https://doi.org/ 10.16324/j.cnki.jcts.2019.05.039. 
[8] Wen, X., Hu, Y.X., Yin, Y.N. (2019). Individualized Evaluation and Promotion Strategy of Regional Higher Education Competitiveness. Modern Education Management, (12): 30-35. https://doi.org/10.16697/j.cnki.xdjygl.2019.12.005.

[9] Dugarova, D., Kimova, S., Kalinina, L. (2015). Educational Audit as an Imperative of Higher Education Program Competitiveness in the Trans-Border Region. Procedia - Social and Behavioral Sciences, 214: 192-200. https://doi.org/10.1016/j.sbspro.2015.11.661.

[10] Nicole, C.J. (2019). Managing for competency with innovation change in higher education: Examining the pitfalls and pivots of digital transformation. Business Horizons, 62(6): 761772. https://doi.org/10.1016/j.bushor.2019.08.002.

[11] Wang, S., Fang, Y. (2012). Higher Education Competitiveness: Model, Index and International Comparison. Educational Research, (7): 122-129.

[12] Plewa, C., Ho, J., Conduit, J., Karpen, I.O. (2016). Reputation in higher education: A fuzzy set analysis of resource configurations. Journal of Business Research, 69(8): 3087-3095. https://doi.org/10.1016/j.jbusres.2016.01.024.

[13] Ezghari, S., Zahi, A., Zenkouar, K. (2017). A new nearest neighbor classification method based on fuzzy set theory and aggregation operators. Expert Systems with Applications, 80: 58-74. https://doi.org/10.1016/j.eswa.2017.03.019.

[14] Li, Z.L., Zhou, Y., Bao, R. (2019). An image classification method based on optimized fuzzy bag-of-words model. Traitement du Signal, 36(3): 239-244. https://doi.org/10.18280/ $\underline{\text { ts. } 360306}$

[15] Najme, M., Behnam, M.H.Z., Mohammad, M.J. (2019). Hybrid task scheduling strategy for cloud computing by modified particle swarm optimization and fuzzy theory. Computers \& Industrial Engineering, 130: 597-633. https://doi.org/10.1016/j.cie.2019.03.006.

[16] Watanabe, T., Yoshikawa, T., Ito, T., Miwa, Y., Shibata, T., Saga, S. (2020). An infiniteresolution grid snapping technique based on fuzzy theory. Applied Soft Computing, 89: 112. https://doi.org/10.1016/j.asoc.2020.106112.

[17] Wolnowska, A.E., Konicki, W. (2019). Multi-criterial analysis of oversize cargo transport through the city, using the AHP method. Transportation Research Procedia, 39: 614-623. https://doi.org/10.1016/j.trpro.2019.06.063.

[18] Calabrese, A., Costa, R., Levialdi, N., Menichini, T. (2019). Integrating sustainability into strategic decision-making: A fuzzy AHP method for the selection of relevant sustainability issues. Technological Forecasting and Social Change, 139: 155-168. https://doi.org/10. 1016/j.techfore.2018.11.005.

[19] Delgado, A., Romero, I. (2016). Environmental conflict analysis using an integrated grey clustering and entropy-weight method: A case study of a mining project in Peru. Environmental Modelling \& Software, 77: 108-121. https://doi.org/10.1016/i.envsoft.2015.12.011.

[20] Mura, M.D., Dini, G. (2019). Optimizing ergonomics in assembly lines: A multi objective genetic algorithm. CIRP Journal of Manufacturing Science and Technology, 27: 31-45. https://doi.org/10.1016/i.cirpj.2019.08.004.

[21] Saad, A.J., Amin, M., Aqib, M.K. (2018). A Critical Review: Shape Optimization of Welded Plate Heat Exchangers based on Grey Correlation Theory. Applied Thermal Engineering, 144: 593-599. https://doi.org/10.1016/j.applthermaleng.2018.08.086.

[22] Balderas, D., Ponce, P., Molina, A. (2019). Convolutional long short-term memory deep neural networks for image sequence prediction. Expert Systems with Applications, 122: 152162. https://doi.org/10.1016/j.eswa.2018.12.055.

[23] Seresht, G., Fayek, N., Robinson, A. (2019) Computational method for fuzzy arithmetic operations on triangular fuzzy numbers by extension principle. International Journal of Approximate Reasoning, 106: 172-193. https://doi.org/10.1016/j.ijar.2019.01.005. 
[24] Karimi, H., Sadeghi-Dastaki, M., Javan, M. (2020). A fully fuzzy best-worst multi attribute decision making method with triangular fuzzy number: A case study of maintenance assessment in the hospitals. Applied Soft Computing, 86: 1-11. https://doi.org/10.1016/ j.asoc. 2019.105882

[25] Nguyen, T.K.S. (2018). A foundation on semigroups of operators defined on the set of triangular fuzzy numbers and its application to fuzzy fractional evolution equations. Fuzzy Sets and Systems, 347: 1-28. https://doi.org/10.1016/j.fss.2018.02.003

\section{Author}

Lin Lin is a teacher at Department of Primary Education of the normal school/branch of Bei Hua University with the title of lecturer. She graduated from Ji Lin Normal University with a master's degree in Ethics. Famous scientific and research teacher in Jilin province. She has been engaged Ideological and political education teaching and educational research for many years. Teaching the course "Teacher Etiquette". Led a provincial education planning project. Participated in three key projects of the provincial "13th five-year plan". Completed on provincial social science project, and participated in three provincial education association projects. She has published 6 academic papers, which have been published in national journals, provincial journals and university journals, among which the national journal papers have won the first prize of provincial excellent achievements in education and science. With strong research ability and rich teaching experience.

Article submitted 2020-04-01. Resubmitted 2020-05-04. Final acceptance 2020-05-07. Final version published as submitted by the authors. 